\title{
Friction Stir Welding of Mild Steel - Tool Durability and Steel Microstructure
}

\author{
A. De ${ }^{1}$, H. K. D. H. Bhadeshia ${ }^{2}$ and T. DebRoy ${ }^{3}$ \\ ${ }^{1}$ Indian Institute of Technology Bombay, ${ }^{2}$ Cambridge University, \\ ${ }^{3}$ The Pennsylvania State University
}

\begin{abstract}
$\underline{\text { Abstract }}$
In previous work, we have established a scheme that exploits a three-dimensional heat and mass flow model to assess tool durability and define the domains of satisfactory tool life in the context of welding difficult aluminium alloys. We now apply this scheme to the friction stir welding of steel, and extend the calculations to cover consequences on the microstructure of the steel while optimizing tool life. This is the first published model that covers both the processing parameters and the consequences on the physical metallurgy of the steel.
\end{abstract}

\section{Introduction}

Friction stir welding (FSW) of aluminium alloys is commercially viable in part because the tools are cost effective and durable. ${ }^{1-5}$ In contrast, the much larger market for welding of steels remains largely out of the reach of FSW because of the high cost and insufficient durability of the tools. ${ }^{6-14}$ Most of the previous studies on steels ${ }^{6-12}$ were conducted on small weld lengths of specimens that precluded any rigorous evaluation of tool durability. A recent review $^{14}$ of the tool materials indicates that severe stresses and high temperatures pose a formidable challenge for the development of cost effective and durable tools for the FSW of hard alloys. As a result, the initial commercial applications of FSW to steels are likely to come from specialised, niche areas where fusion welding clearly has serious difficulties provided the required structure and properties can be achieved by FSW. ${ }^{13}$ Improved tool durability and a metallurgical knowledge base of microstructure and properties of friction stir welded steels are important prerequisites for expanding the reach of FSW to steels.

Since FSW is difficult for hard alloys and not widely used, there is a dearth of data and theory to enable the selection of welding conditions to enhance the tool durability. During FSW of steels, both chemical and mechanical erosion are possible mechanisms of tool degradation ${ }^{15}$ but are not considered in the present work where the structural integrity of the tool is the primary focus. It is emphasised therefore, that the "tool durability" referred to throughout this work does not include erosion induced degradation. Nevertheless, the calculated temperatures and stresses 
that the tool is subjected to, are important variables in chemical and mechanical erosion and can serve as inputs into any future models dealing with progressive degradation of tools.

The experimental estimation of stresses and temperatures experienced by the tool pin during FSW remains a formidable challenge because the pin is embedded within the hot plasticised-alloy and a large number of welding variables affect the process. We have recently showed that the ability of a tool to safely endure stresses at high temperatures can be analyzed using a heat transfer and material flow model for the welding of 7075 aluminium alloy. ${ }^{15}$ The results of the analysis were presented in the form of maps of the tool durability index that showed how the ratio of the shear strength of the tool material and the maximum shear stress experienced by the tool varied with welding variables. The results are made available in easy to use maps for various welding conditions on a fairly large parameter space. It was found that by selecting appropriate welding variables, it is often possible to operate FSW under safe welding conditions to avoid premature tool degradation/failure primarily due to shear. ${ }^{15}$ This paper documents the first effort to enhance the tool durability by focusing on the severity of shear stress it experiences during FSW of a mild steel.

The reported heating and the cooling rates of alloys during FSW fall within the range of reported values in fusion welding. ${ }^{16}$ Therefore, the anticipated phase transformations are unlikely to be significantly different from fusion welding if the cooling rate is the only factor for microstructure evolution. However, two special features distinguish the evolution of microstructure and the resulting properties of friction stir welded steels from those in fusion welding. First, the peak temperatures for FSW are lower than that for fusion welding. As a result, the grain size of austenite that forms in the heat affected zone are often not as large as those for fusion welding. ${ }^{11}$ In addition, severe deformation and flow of plasticised steel alter the stability of austenite in the thermomechanically affected zone because of the stored energy which affects its decomposition to daughter phases. In contrast, the austenite formed during cooling of molten weld metal in fusion welding is hardly affected by any stored energy. This paper documents the first effort to understand quantitatively, the evolution of microstructure of mild steel during FSW.

\section{Methodology}

\section{A. Tool durability index}


During the FSW of steels, temperature and stress can be calculated from a well-tested, three-dimensional heat transfer and visco-plastic flow model. The computational model, used in the present study, solves the equations of conservation of mass, momentum and energy together with two sub-models to estimate local variations in heat generation rate and viscosity. ${ }^{16-20}$ The computational model has correctly predicted independent experimentally measured results of thermal cycles, ${ }^{16-20,23-26}$ torque $^{21-26}$ and traverse force ${ }^{21,26}$ in FSW of aluminium alloys, ${ }^{17,19,21-27}$ steels ${ }^{16,18}$ and a titanium alloy. ${ }^{20}$ Full details of the computational model are available in most of these previous publications. ${ }^{16-27}$

The progressive degradation of the tool may be minimised by focusing on the relative severity of maximum shear stress and peak temperature that the tool experiences for various welding conditions. Since the goal is to compare different welding conditions, calculations are done considering only steady-state operations. Vibration and other abrupt causes of tool degradation are not included for simplicity and the temporal variations of temperatures and stresses during the initial tool insertion or the final tool withdrawal period are neglected. Since the tool pins and the shoulder surface geometries differ widely, a flat shoulder geometry and a cylindrical tool pin without any thread is considered. It is important to evaluate the effects of welding conditions on tool durability before progressing toward more complex tool geometries.

Following Tresca's Yield criterion, the resultant maximum shear stress, $\tau_{\mathrm{m}}$, at any given location on the pin profile is obtained ${ }^{25,26}$ from shear stresses due to bending $\left(\tau_{\mathrm{B}}\right)$ and torsion $\left(\tau_{\mathrm{T}}\right)$ and the normal stress due to bending $\left(\sigma_{\mathrm{B}}\right)$ :

$$
\tau_{\mathrm{m}}=\sqrt{\left(\frac{\sigma_{\mathrm{B}}}{2}\right)^{2}+\left(\tau_{\mathrm{B}}+\tau_{\mathrm{T}} \sin \theta\right)^{2}+\left(\tau_{\mathrm{T}} \cos \theta\right)^{2}}
$$

where $\theta$ is the angle between the radius passing through the location and the welding direction. The procedure for the calculation of $\tau_{\mathrm{B}}, \tau_{\mathrm{T}}$ and the normal stress due to bending $\left(\sigma_{\mathrm{B}}\right)$ has been discussed previously ${ }^{25,26}$ and is not reproduced here. The maximum shear stress, $\tau_{\mathrm{m}}$, at any location on the pin surface depends on variables such as the welding speed, rotational speed and $\theta$. It is shown subsequently that $\tau_{\mathrm{m}}$ has its highest value at $\theta=90^{\circ}$ for a pin with a circular crosssection. The tool durability index is defined as the ratio of the shear strength of the tool material and the maximum shear stress on the tool pin. If $\tau_{\mathrm{m}}$ is much less than the shear strength of the tool material at the peak temperature for the welding variables chosen, the tool is assumed to be 
able to endure the stress and temperature safely. The peak temperature is used to calculate the temperature dependent shear strength of the tool materials for a given set of welding parameters. The values of tool durability index are then plotted in the form of contours so that the effects of tool shoulder diameter and rotational speed, welding speed, and the tool pin radius and length on the tool durability index can be easily determined. Since the pin length depends on the thickness of the workpiece, the tool durability can be enhanced either by ensuring an adequate softening of the workpiece material or increasing the structural strength of the pin. ${ }^{15,23,26}$ While the former can be accomplished with a larger tool shoulder diameter or smaller welding speed, the latter needs an effective increase of the load bearing mass of the pin. ${ }^{15,23,26}$

\section{B. Microstructure}

The thermal cycles computed from the heat transfer and materials flow model are used to calculate the microstructure of the weld zone. For most welding conditions, austenite forms in the entire weld zone and its decomposition during cooling is modelled to determine its final microstructure. A model developed by Jones and Bhadeshia ${ }^{28}$ and adapted later to include bainite $^{29}$ that modified the Johnson-Mehl-Avrami theory to account for the formation of various simultaneous transformation products from austenite decomposition during cooling was used for this purpose. The simultaneous formation of various phases such as the allotriomorphic ferrite, Widmanstätten ferrite and pearlite which compete for untransformed austenite was considered. The model accounts for overlapping interaction of phases such as allotriomorphic ferrite, Widmanstätten ferrite and pearlite that touch each other and the overlapping of the concentration and the temperature fields. There are sub-models in the program, for each of the individual phases in terms of their atomic mechanisms of transformation. For example, the allotriomorphic ferrite and pearlite grow by diffusional transformation whereas Widmanstätten ferrite does so by a paraequilibrium displacive transformation controlled by the partitioning of carbon. The solutes included in the composition of the steel are C, Mn, Si, Ni, Mo, Cr, V, all of which must be in solid solution when the weld is in its austenitic state. The nucleation of various phases and the change in the shape of the transformed region during the growth of Widmanstätten ferrite and the associated strain energy was considered together with the partitioning of carbon into the austenite by diffusion. The method has been validated by calculating fractions of allotriomorphic ferrite, Widmanstätten ferrite and pearlite as a function of chemical composition, austenite grain 
size and thermal cycles. It is important to note that the program is used in the present work without any modification, so there is no fitting involved to accommodate any difficulties in predicting structure. This is because the method has been extensively validated for wrought steels, so if there any peculiarities of FSW then they should be revealed by applying an unadulterated calculation.

It is emphasised that the model used here is radically different from that for welds that involve fusion, where the structure evolves from the liquid state ${ }^{30}$. Friction stir welding in most cases involves only the solid state, so it is appropriate to use a method ${ }^{28,29}$ based on the evolution of structure in the solid-state. As will be seen later, there are complications because some parts of the friction stir weld exist in a plastically deformed state prior to the transformation of austenite, a phenomenon that has not been considered at all in the descriptions of structure of such welds, but is well established in other scenarios involving wrought steels. ${ }^{31-34}$

\section{Results and discussion}

A comparison between the calculated and the measured thermal cycle at a monitoring location $12.7 \mathrm{~mm}$ away from the weld centreline on the advancing side for the welding conditions reported by Lienert et al. ${ }^{7}$ showed good agreement ${ }^{16}$ indicating that the model can be used to calculate temperature profiles and cooling rates in FSW of $1018 \mathrm{C}$-Mn steel. Figure 1 shows that the peak temperatures at the top plane are somewhat higher than that at the bottom plane by about $150 \mathrm{~K}$. However, the cooling rates did not change significantly at various locations. Data used for the calculations are presented in Table I. Figure 2 shows that the cooling rates change significantly with the welding speed at all the monitoring locations. In contrast, the cooling rate has not changed significantly with the rotational speed, although the temperatures are somewhat higher near the shoulder at higher tool rotational speeds. This finding is consistent with the independent observation ${ }^{36}$ that the microstructure is insensitive to changes in the tool rotational speed but is significantly affected by welding speed for the FSW of HSLA 65 steel.

The microstructure calculations were performed at a tool rotational speed of $300 \mathrm{rpm}$ and welding speed of $0.42 \mathrm{~mm} / \mathrm{s}$, for the region next to the pin at the top and middle horizontal planes, where the cooling rates were in the range of 20 and $8 \mathrm{~K} / \mathrm{s}$. The corresponding region at the bottom does not reach a fully austenitic state and these regions were neglected. 
Our calculations considering the appropriate chemical composition (Fe-0.18C-0.82Mn $\mathrm{wt} \%{ }^{7}$ ), cooling rate and the austenite grain size did not generate the microstructures reported by Lienert et al. ${ }^{7}$ for the stir zone. The microstructural study reported uses welding terminology that is different from that in phase transformation theory; thus, polygonal ferrite, ferrite side-plates and ferrite-carbides in reference [7] are here assumed to be allotriomorphic ferrite $(\boldsymbol{\alpha})$, a mixture of Widmanstätten ferrite and bainite $\left(\boldsymbol{\alpha}_{\mathrm{w}}+\boldsymbol{\alpha}_{\mathrm{b}}\right)$, and residual phases such as martensite $\left(\boldsymbol{\alpha}^{\prime}+\gamma\right)$, respectively. It is not possible from the two micrographs available (Fig. 6, ref. 7), to make more than a rough estimate of the phases obtained in the centre of the stir zone and at the top of that zone. These crude estimates are listed in the last two rows of Table II, which also shows that they are quite different from the calculations in the first two rows of this table. The calculations show very little transformation during cooling at the rates expected in the two regions of the stir zone. This is because unlike fusion welds, the stir zone is in fact thermomechanically processed prior to transformation. Such processing introduces defects in the austenite, which then contribute to the chemical free energy change for phase transformations at elevated temperatures. ${ }^{31-34}$

During the hot rolling of mild steels of the kind studied here, the stored energy due to deformation is in the range $21-60 \mathrm{~J} \mathrm{~mol}^{-1}$ as calculated in reference (35). We assume what might be a conservative value of $200 \mathrm{~J} \mathrm{~mol}^{-1}$ in the stir zone; in practice, there will be a complex gradient in this energy corresponding to gradients in the constitutive parameters and a balance between recovery and deformation. It is not the intention here to resolve these issues, but rather to illustrate the importance of this stored energy. Table II (rows 3,4) shows the dramatic effect on the evolution of microstructure, which is now more consistent with the observed structures.

Figure 3 shows the typical variation of various stresses during one rotation of the tool pin as a function of the orientation angle $(\theta)$ with the welding direction. The resultant maximum shear stress is influenced primarily by the shear stresses due to bending and torsion, and attains the maximum at $\theta=90^{\circ}$, when the former is the maximum and both the shear stresses add up vectorially since they are in the same direction. A comparison of Figs 3(a) and (b) shows that both the magnitude and the fluctuation of the resultant maximum shear stress increase significantly with the increase of welding speed from $0.42 \mathrm{~mm} \mathrm{~s}^{-1}$ to $2.1 \mathrm{~mm} \mathrm{~s}^{-1}$. Increase in the welding speed reduces the heat input per unit length resulting in lower peak temperature, higher traverse force and higher stresses on the pin. 
Figure 4 shows the peak temperatures and maps of tool durability index for various tool shoulder diameters and rotational speed for the FSW of C-Mn 1018 steel. A comparison of the solid and dashed lines in Fig. 4(a) shows the effect of welding speed on the peak temperature. An increase in the welding speed reduces the rate of heat generation per unit length of weld resulting in relatively cooler and harder material around the tool pin. As a result, the stresses on the tool increase because the workpiece material becomes harder and consequently, the value of tool durability index, shown in Fig. 4(b), decreases with increase in welding speed.

Figure 5 shows the effect of plate thickness on the peak temperature and tool durability index. During FSW of thick plates, there is considerable decrease in temperature away from the tool shoulder and the lower part of the pin encounters cooler and stronger workpiece. The decrease in the peak temperature is shown in Fig. 5(a). As a result, the tool encounters larger stresses during welding of thicker plates and thus, the tool durability index decreases with increase in the plate thickness (Fig. 5b).

Figure 6 shows the effect of pin diameter on the peak temperatures and tool durability index. An increase in the pin diameter increases the rate of heat generation per unit length of weld resulting in an increase of the peak temperature (Fig. 6a). As a result, the stresses on the tool decrease because the workpiece material becomes softer and thus, the value of tool durability index, shown in Fig. 6(b), increases with increase in the pin diameter.

\section{Summary and Conclusions}

Cooling rates during FSW of mild steel are lower than the highest cooling rates reported during GTA welding. In the 1073 to $773 \mathrm{~K}$ (800 to $500{ }^{\circ} \mathrm{C}$ ) temperature range, the cooling rates are significantly affected by the welding speed but not by the tool rotational speed.

It has been demonstrated that the microstructure of the weld zone during FSW of 1018 steel can be estimated if account is taken of the deformation of the austenite prior to its transformation. This is quite unlike fusion welds where the austenite is essentially free from defects. However, the calculations highlight a need for the better quantitative characterisation of the microstructural constituents of the stir zone of friction stir welds in steels, a characterisation based on the mechanisms of transformation of the individual phases. Furthermore, this needs to be done as a function of position in the stir zone since the deformation characteristics are not expected to be uniform in that zone. Computational models are in this sense more advanced than 
experimental data, since the stored energy gradients within the stir zone can in principle be calculated today.

Given the absence of fusion in friction stir welding, it is not necessary to create new schemes to calculate microstructures but to apply those already available for wrought steels. The scheme presented in reference (37) is ideal in the sense that the structures are defined in terms of phase transformation theory essential in the calculation of structure.

For the FSW of mild steel, an increase in either the tool shoulder diameter or the tool rotational speed increase workpiece temperature and hence, enhances tool durability. A faster welding speed reduces peak temperature, increases stresses on the tool and thus, reduces tool durability. Thicker plates also decrease tool durability for the same reasons. In contrast, thicker tool pins increase tool durability because of enhanced structural stiffness.

\section{References}

[1] W. M. Thomas: 'Friction stir welding - recent developments', Mater. Sci. Forum., 2003, 426, (4), 229-236.

[2] R. S. Mishra and Z. Y. Ma: 'Friction stir welding and processing', Mater. Sci. Eng. R, 2005, 50, (1-2), 1-78.

[3] R. Nandan, T. DebRoy and H. K. D. H. Bhadeshia: Recent advances in friction-stir welding - process, weldment structure and properties: Prog. Mater. Sci., 2008, 53, (6), 980-1023.

[4] P. L. Threadgill, A. J. Leonard, H. R. Shercliff and P. J. Withers: 'Friction stir welding of aluminium alloys', Int. Mater. Rev., 2009, 54, (2), 49-93.

[5] T. DebRoy and H. K. D. H. Bhadeshia: 'Friction stir welding of dissimilar alloys - a perspective', Sci. Technol. Weld. Joining, 2010, 15, (4), 266-270.

[6] A. P. Reynolds, W. Tang, M. Possada and J. Deloch: 'Friction stir welding of DH36 steel', Sci. Technol. Weld. Joining, 2003, 8, (6), 455-460.

[7] T. J. Lienert, W. L. Stellwag, Jr., B. B. Grimmett and R. W. Warke: 'Friction stir welding studies on mild steel', Weld. J., 2003, 82, (1), 1s-9s.

[8] P. J. Konkol, J. A. Mathers, R. Johnson and J. R. Pickens: 'Friction stir welding of HSLA65 steel for shipbuilding', Journal of ship production, 2003, 19, (3), 159-164. 
[9] A. P. Reynolds, W. Tang, T. Gnaupel-Herold and H. Prask: 'Structure, properties and residual stress of 304L stainless steel friction stir welds'Scr. Mater., 2003, 48, (9), 12891294.

[10] W. Gan, Z. T. Li and S. Khurana: 'Tool materials selection for friction stir welding of L80 steel', Sci. Technol. Weld. Joining, 2007, 12, (7), 610-613.

[11] M. Matsushita, Y. Kitani, R. Ikeda, M. Ono, H. Fuji and Y. D. Chung: 'Development of friction stir welding of high strength steel sheet', Sci. Technol. Weld. Joining, 2011, 16, (2), $181-187$.

[12] G. Cam: 'Friction stir welded structural materials: beyond Al-alloys' Int. Mater. Rev., 2011, 56 (1), 1-48.

[13] H. K. D. H. Bhadeshia and T. DebRoy: 'Critical assessment: friction stir welding of steels', Sci. Technol. Weld. Joining, 2009, 14, (3), 193-196.

[14] R. Rai, A. De, H. K. D. H. Bhadeshia and T. DebRoy: 'Review: friction stir welding tools', Sci. Technol. Weld. Joining, 2011, 16, (4), 325-342.

[15] T. DebRoy, A. De, H. K. D. H. Bhadeshia, V. D. Manvatkar and A. Arora: 'Tool durability maps for friction stir welding of an aluminium alloy', Proceedings of the Royal Society A, 2012, 468, 3552-3570.

[16] R. Nandan, G. G. Roy, T. J. Lienert and T. DebRoy: 'Three-dimensional heat and material flow during friction stir welding of mild steel', Acta Mater., 2007, 55, 883-895.

[17] R. Nandan, G. G. Roy and T. DebRoy: 'Numerical simulation of three dimensional heat transfer and plastic flow during friction stir welding of aluminium alloys', Metall. Mater. Trans. A, 2006, 37A, 1247-1259.

[18] R. Nandan, G. G. Roy, T. Lienert and T. DebRoy: 'Numerical simulation of three dimensional heat transfer and plastic flow during friction stir welding of stainless steel', Sci. Technol. Weld. Joining, 2006, 11, (5), 526-537.

[19] R. Nandan, B. Prabu, A. De and T. DebRoy, 'Improving reliability of heat transfer and fluid flow calculations in friction stir welding of dissimilar aluminium alloys', Weld. J., 2007, 86, (10), 313s-322s.

[20] R. Nandan, T. J. Lienert and T. DebRoy: 'Toward reliable calculations of heat and plastic flow during friction stir welding of Ti-6Al-4V alloy', Int. J. Mater. Research, 2008, 99, (4), 434-444. 
[21] A. Arora, R. Nandan, A.P. Reynolds and T. DebRoy: 'Torque, power requirement and stir zone geometry in friction stir welding through modeling and experiments', Scr. Mater., 2009, 60, 13-16.

[22] A. Arora, T. DebRoy and H. K. D. H. Bhadeshia: 'Back of the envelope calculations in friction stir welding - velocities, peak temperature, torque, and hardness', Acta Mater., 2011, 59, (5), 2020-2028.

[23] M. Mehta, A. Arora, A. De and T. DebRoy: 'Tool geometry for friction stir welding optimum shoulder diameter', Metall. Mater. Trans. A, 2011, 42A, (9), 2716-2722.

[24] V. D. Manvatkar, A. Arora, A. De and T. DebRoy: 'Neural network models for peak temperature, torque, traverse force, bending stress and maximum shear stress during friction stir welding', Sci. Technol. Weld. Joining, 2012, 17, (6), 460-466.

[25] M. Mehta, A. De and T. DebRoy: 'Probing load bearing capacity of circular and noncircular tool pins in friction stir welding', Proceeding of the $9^{\text {th }}$ International Conference on "Trends in Welding Research", held on June 04 - 08, 2012, Chicago, USA, ASM international, Materials Park, Ohio, 2013, 563-571.

[26] A. Arora, M. Mehta, A. De and T. DebRoy: 'Load bearing capacity of tool pin during friction stir welding', Int. J. Adv. Manuf. Technol., 2012, 61, (9), 911-920.

[27] A. Arora, A. De and T. DebRoy: 'Toward optimum friction stir welding tool diameter', Scr. Mater., 2011, 64, (1), 9-12.

[28] S. J. Jones and H. K. D. H. Bhadeshia: 'Kinetics of the simultaneous decomposition of austenite into several transformation products' Acta Mater., 1997, 45, (7), 2911-2920.

[29] J. Chen, H. K. D. H. Bhadeshia, S. Hasler, H. Roelofs, U. Ulrau, 'Complete calculation of microstructure' New Developments on Metallurgy and Applications of High Strength Steels, Buenos Aires, Argentina, pub. Wiley, New Jersey, USA, 2008, pp. 749-759.

[30] H. K. D. H. Bhadeshia and L.-E. Svensson, 'Modelling the evolution of microstructure in steel weld metal' Mathematical Modelling of Weld Phenomena, eds H. Cerjak and K. E. Easterling, The Institute of Materials, London, 1993, pp. 109-182.

[31] Y. Saito, T. Enami, T. Tanaka, 'Mathematical model of hot deformation with reference to microstructural changes during rolling in plate mill' Trans. ISIJ, 1985, 25, 1146-1155. 
[32] X. D. Liu and L. P. Karjalainen, 'Effect of processing parameters on the stored energy during multipass deformation of $\mathrm{Nb}$ bearing steel', Mechanical Working and Steel Processing Conference Proceedings, AIME, USA, 1996, pp. 769-776.

[33] C. M. Sellars, 'Recrystallisation of metals during hot deformation', Phil. Trans. Royal Society A, 1978, 288, 147-158.

[34] C. M. Sellars, 'Modelling microstructural development during hot rolling', Materials Science and Technology, 1990, 6, 1072-1081.

[35] S. V. Parker, Modeling of phase transformation in hot-rolled steels, Ph.D. thesis, University of Cambridge, 1997.

[36] D. M. Failla II: 'Friction stir welding and microstructure simulation of HSLA-65 and austenitic stainless steels', M.S. Thesis, Ohio State University, 2009, pp. 1-160.

[37] H. K. D. H. Bhadeshia and J. W. Christian: 'The bainite transformation in steels', Metall. Trans. A, 1990, 21, 767-797. 


\section{List of Tables}

Table I Data used for the calculations of heat transfer and material flow during FSW of 1018 steel.

Table II: Computed phase fractions of allotrimorphic ferrite $(\alpha)$, pearlite $(\mathrm{P})$, Widmanstätten ferrite $\left(\alpha_{\mathrm{w}}\right)$, bainite and martensite and austenite $\left(\alpha^{\prime}+\gamma\right)$ for the stir zone of the weld of 1018 steel for different cooling rates assuming zero and $200 \mathrm{~J} \mathrm{~mol}^{1}$ stored energy contributing to the chemical free energy change.

\section{List of Figures}

Fig. 1 The computed thermal cycles at the top and bottom planes at various monitoring locations during FSW of 1018 steel. Welding speed: $0.42 \mathrm{~mm} / \mathrm{s}$ and tool rotational speed: $450 \mathrm{rpm}$.

Fig. 2 The computed thermal cycles for various welding speeds, $0.42,1.05$ and $2.1 \mathrm{~mm} / \mathrm{s}$ from left to right during FSW of 1018 steel at tool rotational speed of $450 \mathrm{rpm}$.

Fig. 3 Variation of fluctuating stress components - normal $\left(\sigma_{\mathrm{B}}\right)$ and shear $\left(\tau_{\mathrm{B}}\right)$ stresses due to bending, shear stress $\left(\tau_{\mathrm{T}}\right)$ due to torsion, and the resultant maximum shear stress $\left(\tau_{\max }\right)$ for one complete rotation of the tool during FSW of $6.35 \mathrm{~mm}$ thick C-Mn 1018 steel at a rotational speed of $450 \mathrm{rpm}$ and at two different welding speeds of (a) $0.42 \mathrm{~mm} \mathrm{~s}^{-1}$ and (b) $2.1 \mathrm{~mm} \mathrm{~s}^{-1}$ using straight cylindrical pin. Pin length, tool shoulder and pin diameters are $6.22 \mathrm{~mm}, 15 \mathrm{~mm}$ and $7.9 \mathrm{~mm}$, respectively.

Fig. 4 A comparison of (a) peak temperature (K) and (b) tool durability index for FSW of 6.35 $\mathrm{mm} 1018$ steel at two different welding speeds $1.05 \mathrm{~mm} / \mathrm{s}$ (solid black line) and $2.1 \mathrm{~mm} / \mathrm{s}$ (dashed blue line).

Fig. 5 A comparison of (a) peak temperature (K) and (b) tool durability index for FSW of 1018 steel at a welding speed of $1.05 \mathrm{~mm} / \mathrm{s}$ for two different plate thicknesses $6.35 \mathrm{~mm}$ (solid black line) and $9.75 \mathrm{~mm}$ (dashed blue line).

Fig. 6 A comparison of (a) peak temperature (K) and (b) tool durability index for FSW of 6.35 $\mathrm{mm}$ thick 1018 steel at a welding speed of $2.1 \mathrm{~mm} / \mathrm{s}$ for two different pin diameters 7.9 $\mathrm{mm}$ (solid black line) and $9.0 \mathrm{~mm}$ (dashed blue line). 
Table I Data used for the calculations of heat transfer and material flow during FSW of 1018 steel.

\begin{tabular}{|c|c|c|}
\hline \multicolumn{2}{|c|}{ Workpiece and tool materials } & C-Mn 1018 Steel, W-0.4\%Re \\
\hline \multicolumn{2}{|c|}{ Tool shoulder and pin diameters, $\mathrm{mm}$} & $(15,18,21,24),(7.9,9.0)$ \\
\hline \multicolumn{2}{|l|}{ Workpiece thickness, mm } & $6.35,9.75$ \\
\hline \multicolumn{2}{|c|}{ Tool rotational speed, RPM } & $300,450,600,750,900$ \\
\hline \multicolumn{2}{|l|}{ Welding speed, $\mathrm{mm} \mathrm{s}^{-1}$} & $0.042,1.05,2.10$ \\
\hline \multicolumn{2}{|l|}{ Axial pressure, $\mathrm{MPa}$} & 65.9 \\
\hline \multicolumn{2}{|c|}{ Workpiece solidus temperature, $\mathrm{K}$} & 1745 \\
\hline Specific heat, $\mathrm{J} \mathrm{kg}^{-1} \mathrm{~K}^{-1}$ & \multicolumn{2}{|c|}{$\begin{array}{l}347.27+62.34 \exp (T / 471.706) \text { for } \mathrm{T}<1073 \mathrm{~K} \\
962.32 \text { for } \mathrm{T} \geq 1073 \mathrm{~K}\end{array}$} \\
\hline 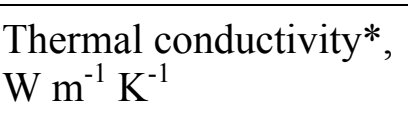 & \multicolumn{2}{|c|}{$\begin{array}{l}63.1-0.032 \times \mathrm{T} \text { for } \mathrm{T}<1073 \mathrm{~K} \\
27.2 \times\{1.0+(\mathrm{T}-1073) /(1745-1073)\} \text { for } \mathrm{T} \geq 1073 \mathrm{~K}\end{array}$} \\
\hline Yield stress, MPa & \multicolumn{2}{|c|}{$\begin{array}{l}111.0+1.11 \times \mathrm{T}-0.0019 \times \mathrm{T}^{2}+7.5 \times 1 \mathrm{e}-7 \times \mathrm{T}^{3} \text { for } \mathrm{T}<1175 \mathrm{~K} \\
10.0 \text { for } \mathrm{T} \geq 1175 \mathrm{~K}\end{array}$} \\
\hline
\end{tabular}

**Pin length is always taken $0.15 \mathrm{~mm}$ shorter than the plate thickness

Table II: Computed phase fractions of allotrimorphic ferrite $(\boldsymbol{\alpha})$, pearlite $(\mathbf{P})$, Widmanstätten ferrite $\left(\alpha_{w}\right)$, bainite and martensite and austenite $\left(\alpha^{\prime}+\gamma\right)$ for the stir zone of the weld of 1018 steel for different cooling rates assuming zero and $200 \mathrm{~J} \mathrm{~mol}^{-1}$ stored energy contributing to the chemical free energy change.

\begin{tabular}{|l|c|c|c|c|c|c|}
\hline & $\mathrm{K.s}^{1}$ & $\boldsymbol{\alpha}$ & $\mathbf{P}$ & $\boldsymbol{\alpha}_{\mathbf{w}}$ & $\boldsymbol{\alpha}_{\mathbf{b}}$ & $\boldsymbol{\alpha}^{\mathbf{}+\boldsymbol{\gamma}}$ \\
\hline Calculated, zero stored energy & 8 & 0.10 & 0.00 & 0.07 & 0.04 & 0.79 \\
\hline Calculated, zero stored energy & 20 & 0.06 & 0.00 & 0.00 & 0.07 & 0.87 \\
\hline Calculated including stored energy & 8 & 0.24 & 0.00 & 0.54 & 0.00 & 0.22 \\
\hline Calculated including stored energy & 20 & 0.17 & 0.00 & 0.31 & 0.01 & 0.51 \\
\hline Estimated from [7] & 8 & 0.2 & & \multicolumn{2}{|c|}{0.4} & 0.4 \\
\hline Estimated from [7] & 20 & 0 & \multicolumn{3}{|c|}{0.8} & 0.2 \\
\hline
\end{tabular}



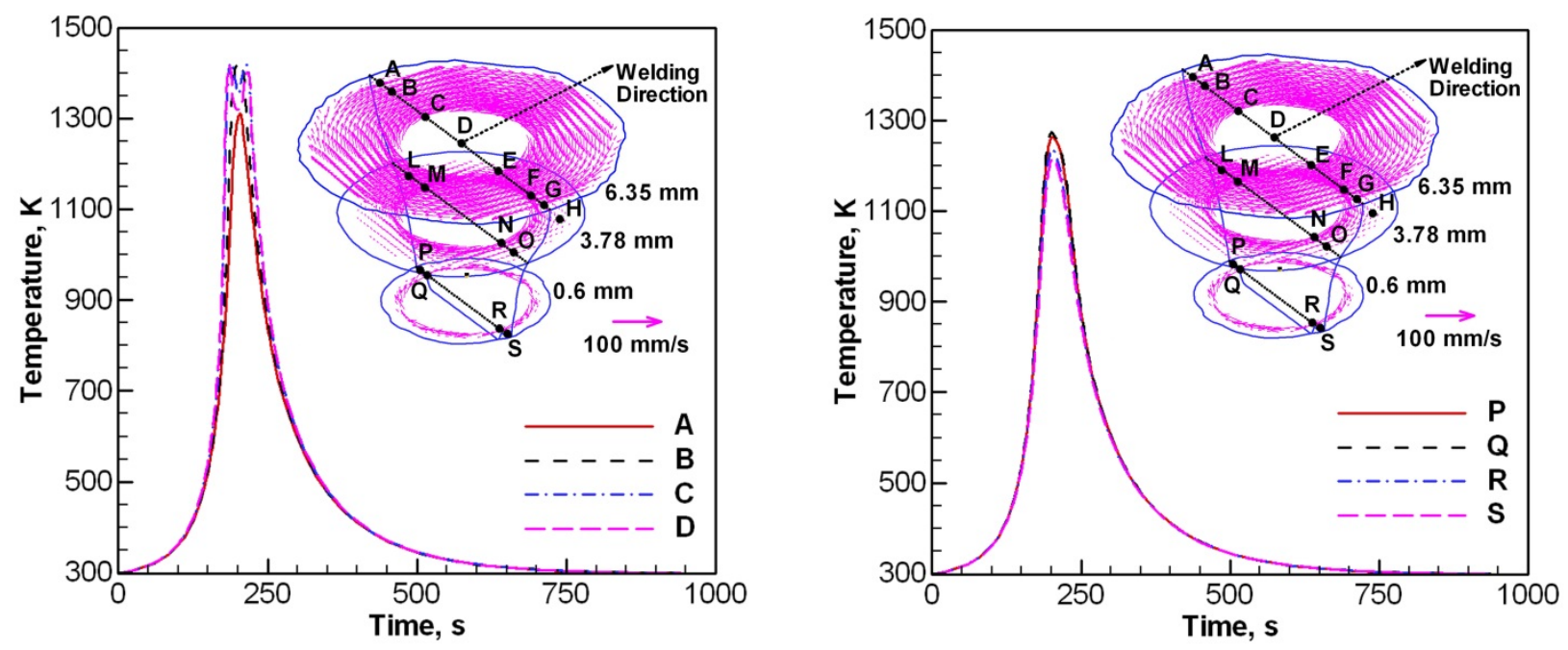

Fig. 1 The computed thermal cycles at the top and bottom planes at various monitoring locations during FSW of 1018 steel. Welding speed: $0.42 \mathrm{~mm} / \mathrm{s}$ and tool rotational speed: $450 \mathrm{rpm}$. 

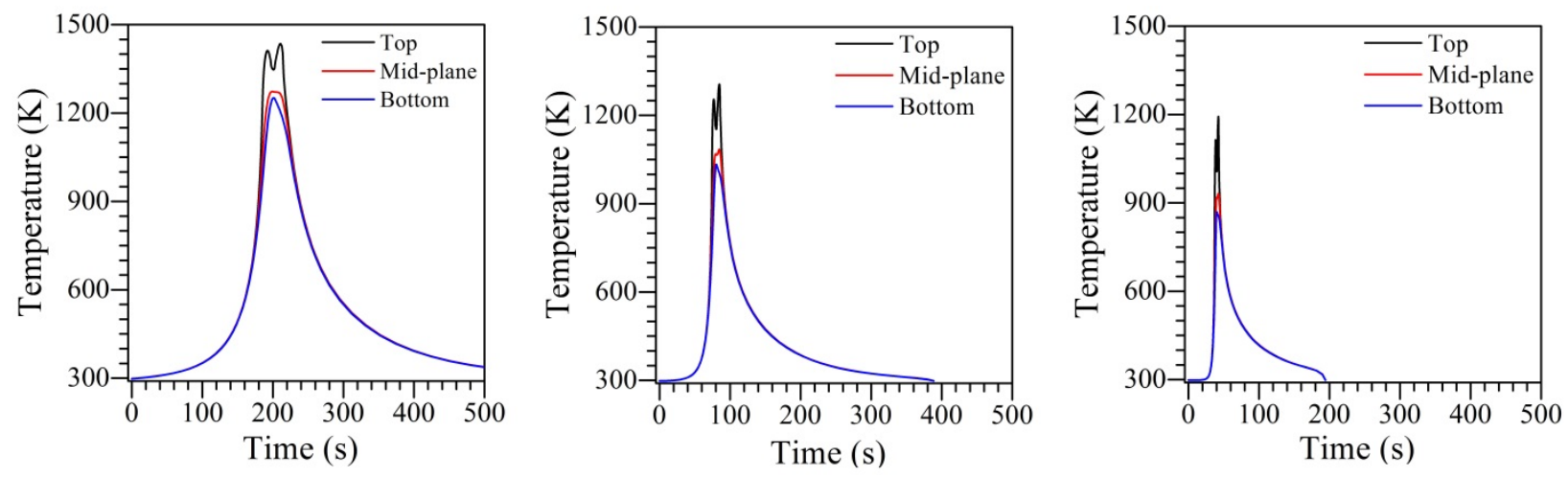

Fig. 2 The computed thermal cycles for various welding speeds, $0.42,1.05$ and $2.1 \mathrm{~mm} / \mathrm{s}$ from left to right during FSW of 1018 steel at tool rotational speed of $450 \mathrm{rpm}$. 

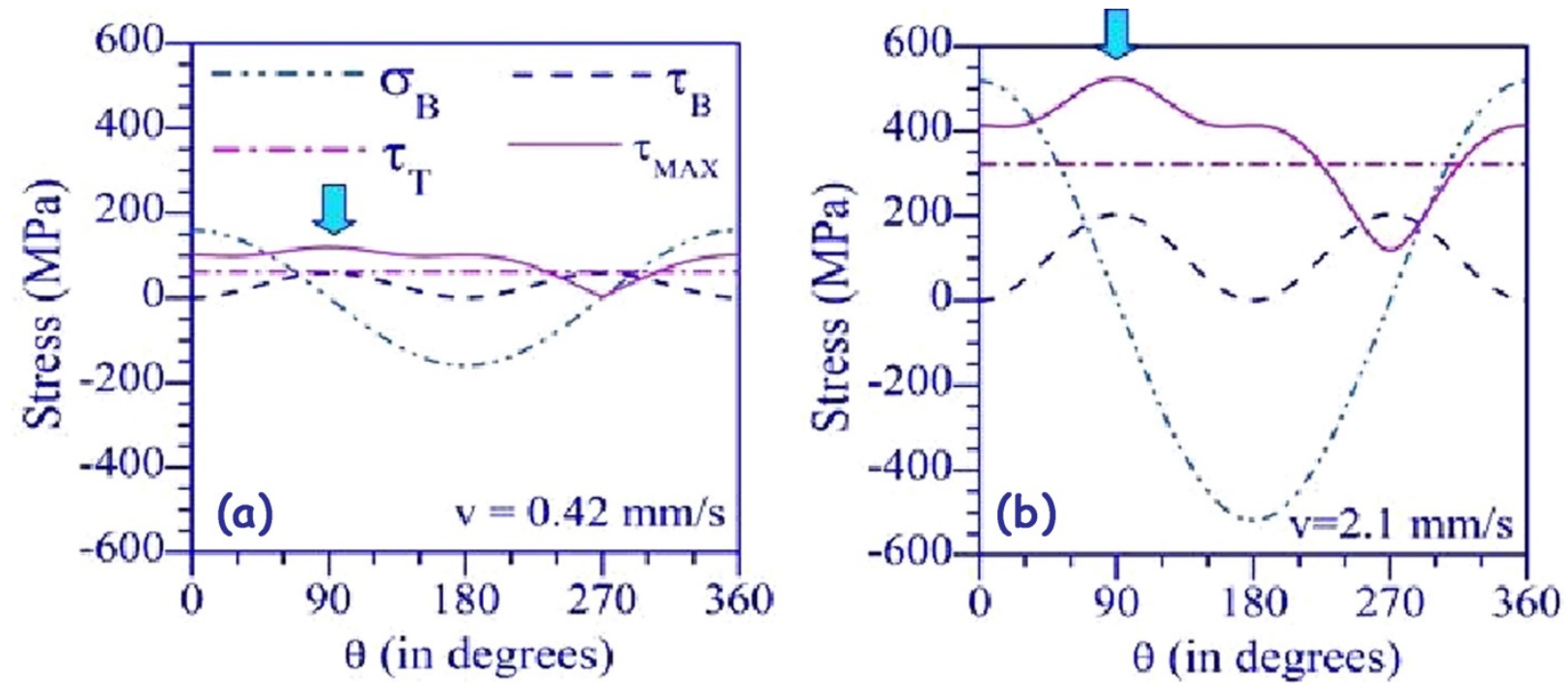

Fig. 3 Variation of fluctuating stress components - normal $\left(\sigma_{\mathrm{B}}\right)$ and shear $\left(\tau_{\mathrm{B}}\right)$ stresses due to bending, shear stress $\left(\tau_{\mathrm{T}}\right)$ due to torsion, and the resultant maximum shear stress $\left(\tau_{\max }\right)$ for one complete rotation of the tool during FSW of $6.35 \mathrm{~mm}$ thick C-Mn 1018 steel at a rotational speed of $450 \mathrm{rpm}$ and at two different welding speeds of (a) $0.42 \mathrm{~mm} \mathrm{~s}^{-1}$ and (b) $2.1 \mathrm{~mm} \mathrm{~s}^{-1}$ using straight cylindrical pin. Pin length, tool shoulder and pin diameters are $6.22 \mathrm{~mm}, 15 \mathrm{~mm}$ and $7.9 \mathrm{~mm}$, respectively. 

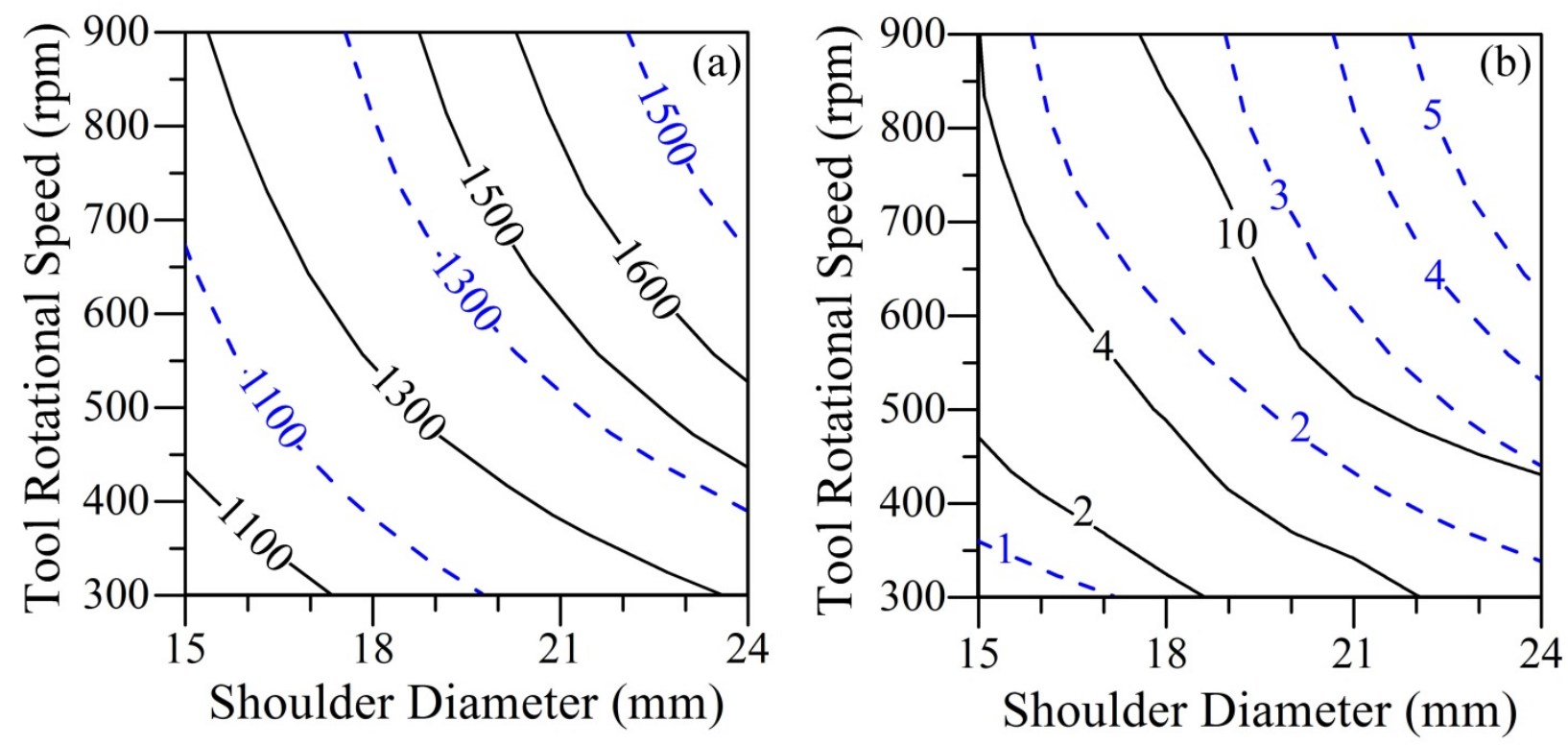

Fig. 4 A comparison of (a) peak temperature (K) and (b) tool durability index for FSW of 6.35 $\mathrm{mm} 1018$ steel at two different welding speeds $1.05 \mathrm{~mm} / \mathrm{s}$ (solid black line) and $2.1 \mathrm{~mm} / \mathrm{s}$ (dashed blue line). 

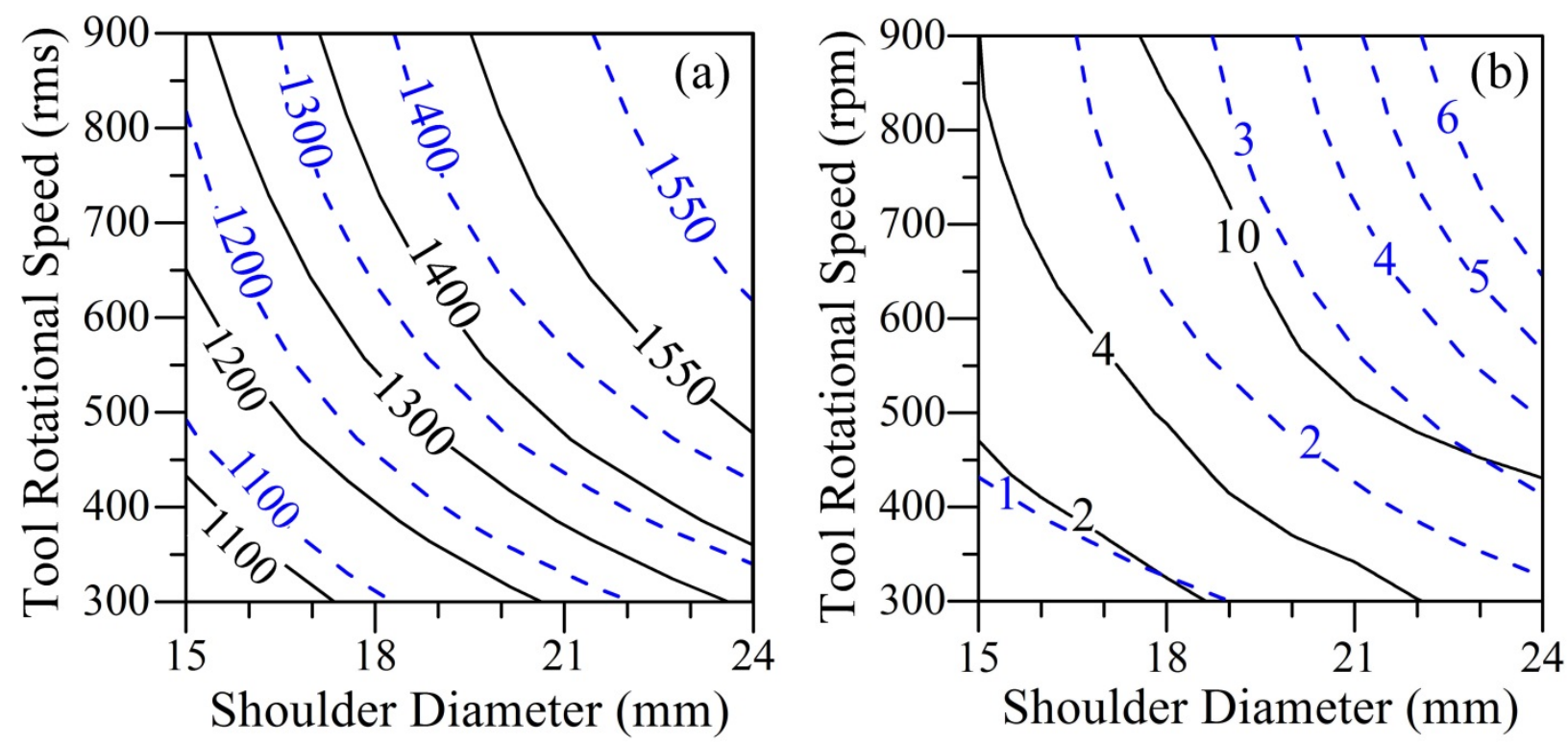

Fig. 5 A comparison of (a) peak temperature (K) and (b) tool durability index for FSW of 1018 steel at a welding speed of $1.05 \mathrm{~mm} / \mathrm{s}$ for two different plate thicknesses $6.35 \mathrm{~mm}$ (solid black line) and $9.75 \mathrm{~mm}$ (dashed blue line). 

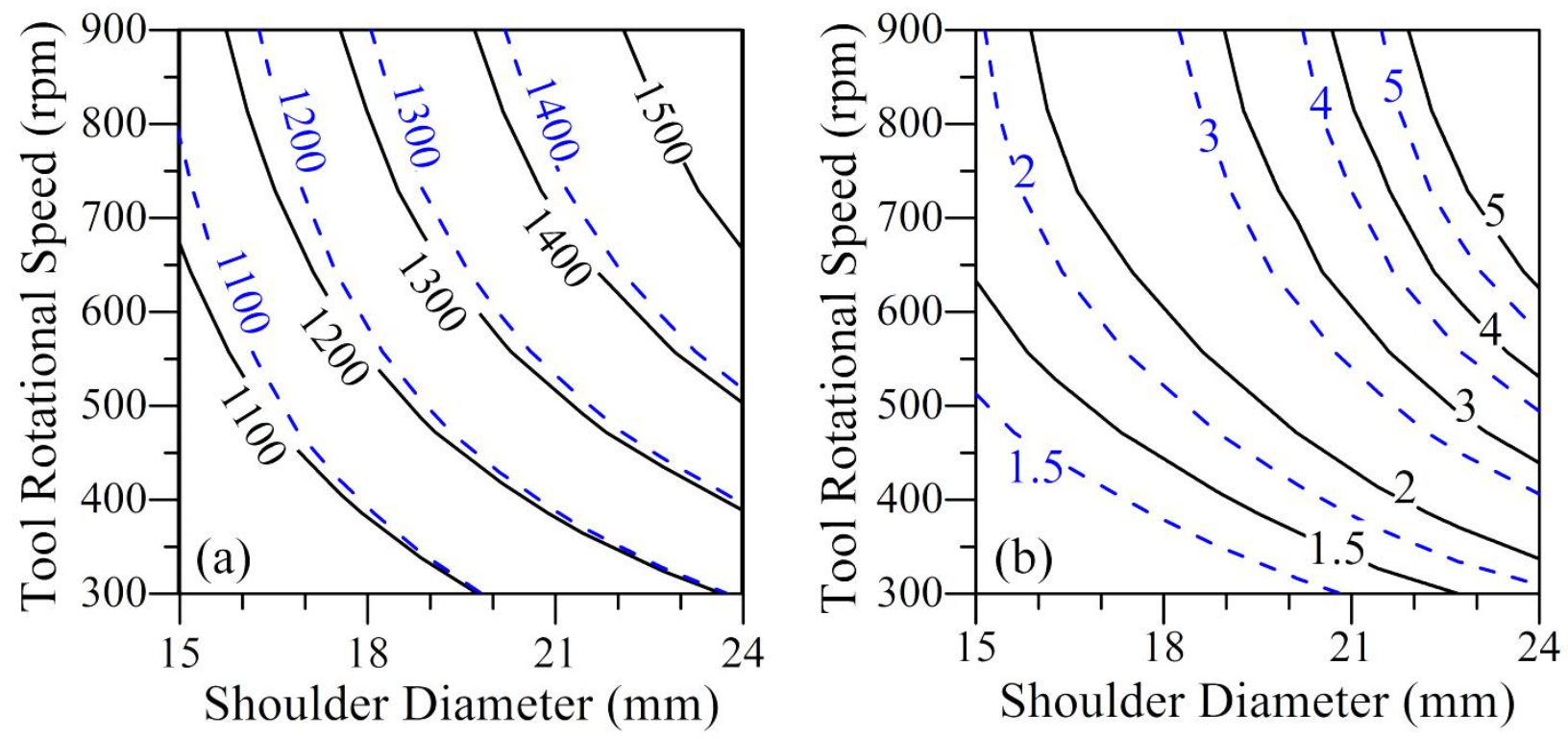

Fig. 6 A comparison of (a) peak temperature (K) and (b) tool durability index for FSW of 6.35 $\mathrm{mm}$ thick 1018 steel at a welding speed of $2.1 \mathrm{~mm} / \mathrm{s}$ for two different pin diameters 7.9 $\mathrm{mm}$ (solid black line) and $9.0 \mathrm{~mm}$ (dashed blue line). 